\title{
InGaAsN as Absorber in APDs for 1.3 micron Wavelength Applications
}

\author{
J. S. Ng ${ }^{\mathrm{a}}$, S. L. Tan ${ }^{\mathrm{a}}$, Y. L. Goh ${ }^{\mathrm{a}}$, C. H. Tan ${ }^{\mathrm{a}}$, J. P. R. David ${ }^{\mathrm{a}}$, J. Allam ${ }^{\mathrm{b}}$, S. J. Sweeney ${ }^{\mathrm{b}}$, and A. \\ R. Adams ${ }^{\mathrm{b}}$ \\ ${ }^{\mathrm{a}}$ Department of Electronic and Electrical Engineering, University of Sheffield, \\ Mappin Street, Sheffield S1 3JD, UK. Email: j.s.ng@sheffield.ac.uk \\ ${ }^{\mathrm{b}}$ Advanced Technology Institute, Faculty of Engineering \& Physical Sciences, \\ University of Surrey, Guildford, Surrey GU2 7XH, UK.
}

Two issues with using InGaAsN as absorber in avalanche photodiodes (APDs) for $1310 \mathrm{~nm}$ wavelength applications are addressed here. Firstly, we demonstrated InGaAsN p-i-n diodes with stable photoresponse around $1310 \mathrm{~nm}$ but reverse leakage current density slightly above the acceptable limit of $\sim 0.2 \mathrm{~mA} / \mathrm{cm}^{2}$ at $150 \mathrm{kV} / \mathrm{cm}$. We also investigated whether or not InGaAsN as absorber is compatible with $\mathrm{Al}_{0.8} \mathrm{Ga}_{0.2} \mathrm{As}$ (the proposed avalanche material in our separate-absorption-multiplication APD design) in terms of the relationship between $\alpha$ and $\beta$ in InGaAsN. Our observations suggest $\alpha \sim \beta$ in InGaAsN, making it compatible with $\mathrm{Al}_{0.8} \mathrm{Ga}_{0.2} \mathrm{As}$.

I. Introduction

Current avalanche photodiodes (APDs) for telecommunication systems operating at $1310 / 1550 \mathrm{~nm}$ use InP and $\mathrm{In}_{0.53} \mathrm{Ga}_{0.47} \mathrm{As}$ in their multiplication and absorption layers, respectively. The upper limit of these APD gain-bandwidth products $(\sim 150 \mathrm{GHz})$ is mainly due to the minimum InP multiplication layer thickness required to avoid excessive band-to-band tunnelling current [1]. Although $\operatorname{In}_{0.52} \mathrm{Al}_{0.48} \mathrm{As}$ (lattice-matched to $\mathrm{InP})$ offers a slightly larger band gap $(1.4 \mathrm{eV})$ compared to $\operatorname{InP}(1.35 \mathrm{eV})$ and hence a thinner $\operatorname{In}_{0.52} \mathrm{Al}_{0.48} \mathrm{As}$ multiplication layer for the same tunnelling current level, the gain-bandwidth products of $\operatorname{In}_{0.53} \mathrm{Ga}_{0.47} \mathrm{As}$ $/ \mathrm{In}_{0.52} \mathrm{Al}_{0.48} \mathrm{As}$ APD are still limited to $\sim 180 \mathrm{GHz}$ [2].

It is therefore desirable for a multiplication layer material to have a bandgap much larger and excess noise performance comparable to, if not better than, those of InAlAs. $\mathrm{Al}_{0.8} \mathrm{Ga}_{0.2} \mathrm{As}$ (lattice-matched to $\mathrm{GaAs}$ ) is a promising candidate because its (indirect) bandgap is $2.2 \mathrm{eV}$ and its excess noise characteristics exhibits low effective ionization coefficients ratio, $k_{\text {eff, for thin }}$ avalanche layers [3]. As expected from its bandgap, $\mathrm{Al}_{0.8} \mathrm{Ga}_{0.2} \mathrm{As}$ p-i-n diodes with i-region thinner than $100 \mathrm{~nm}$ showed reverse leakage currents free from bandto-band tunnelling currents [3]. This is a much lower limit than that of InP and InAlAs, which is close to 200nm. $\mathrm{Al}_{0.8} \mathrm{Ga}_{0.2} \mathrm{As}$ APDs not only promise high speed and low noise performance, but are also compatible with GaAs substrates, which are larger in size and cheaper than InP substrates.

In order to realize $\mathrm{Al}_{0.8} \mathrm{Ga}_{0.2} \mathrm{As}$ APDs for $1310 / 1550$ nm wavelength, GaInNAs with long cut-off wavelength, $\lambda_{c}$, in photoresponse and with acceptable reverse leakage currents [4] can be used as the absorber in Separate-Absorption-Multiplication (SAM) APDs. As dark current increases with decreasing GaInNAs bandgap [4], it is logical to achieve $1310 \mathrm{~nm}$ wavelength operation first before extending to $1550 \mathrm{~nm}$.

Although many GaInNAs photodiodes have been reported to show photon detection (not $\lambda_{c}$ ) beyond $1310 \mathrm{~nm}$, few exhibited relative constant photoresponse of $\sim 1.31 \mu \mathrm{m}$ (more specifically, 1260 to $1360 \mathrm{~nm}$ ), which is required for APDs used in optical communication systems. None of these GaInNAs photodiodes meet the reverse leakage current density requirement for SAM APDs. The upper limit is $\sim 0.2 \mathrm{~mA} / \mathrm{cm}^{2}$ at $150 \mathrm{kV} / \mathrm{cm}$, corresponding to $\sim 1 \mathrm{nA}$ for a $30 \mu \mathrm{m}$ diameter diode.

In designing SAM APDs, consideration should also be given to whether or not the absorber and the avalanche materials are compatible in terms of their ionization coefficients of electrons and holes, $\alpha$ and $\beta$, respectively. As $\alpha>\beta$ in $\mathrm{Al}_{0.8} \mathrm{Ga}_{0.2} \mathrm{As}$, a compatible absorber material should not have $\alpha<\beta$ [5]. Yet, it was predicted that in GaInNAs, the electron-initiated impact ionization process may be suppressed, resulting in $\alpha<<$ $\beta$ [6]. So far, there has been no experimental report to investigate this prediction.

In this paper, we address the above two issues concerned with using GaInNAs as absorber in a SAM APD. The first is to improve the photoresponse of GaInNAs material whilst satisfying the leakage current 
limit. The second is to obtain experimental evidence for the relationship between $\alpha$ and $\beta$.

\section{Photoresponse}

In our previous work [4], a p-i-n diode wafer (wafer $\mathrm{C}$ in Ref [4]) that detects photons at wavelengths up to $1400 \mathrm{~nm}$ and satisfies the leakage current limit was demonstrated using the composition of $\mathrm{Ga}_{0.90} \operatorname{In}_{0.10} \mathrm{~N}_{0.038} \mathrm{As}_{0.962}$. In this work we report a new $\mathrm{p}$ i-n diode wafer with increased indium and nitrogen fractions to increase the photoresponse wavelength limit. The new wafer structure, summarized in Table 1, differs from the previous wafer only in the absence of the AlAs layer. The composition for the new wafer was nominally $\mathrm{Ga}_{0.88} \mathrm{In}_{0.12} \mathrm{~N}_{0.042} \mathrm{As}_{0.958}$ to give a bandgap of $0.92 \mathrm{eV}$ at room temperature, based on the $0.92 \mathrm{eV}$ bandgap at $0 \mathrm{~K}$ as calculated by Bellaiche [7].

X-ray diffraction curves indicated lattice-mismatch (between the GaInNAs peak and the GaAs substrate peak) ranging from $-1.2 \times 10^{-3}$ to $+1.3 \times 10^{-3}$ from the centre to the edge of the wafer. Using linear interpolation for the lattice constant of GaInNAs, the corresponding fractions for nitrogen are 4.9 and 3.7\%, respectively, which are close to the $4.2 \%$ intended.

Circular mesa diodes with four different sizes were fabricated from the wafer using photolithography and wet chemical etching. Reverse dark Current-Voltage (I$\mathrm{V})$ and Capacitance-Voltage $(\mathrm{C}-\mathrm{V})$ characteristics were measured from these diodes at room temperature. Reverse dark currents of the different sized diodes scaled with diode area so bulk dark current density, $J$, versus bias was obtained.

$\mathrm{C}-\mathrm{V}$ data were needed to deduce the unintentional doping (u.i.d.) level in the i-GaInNAs layer. Full depletion was achieved from $-2 \mathrm{~V}$ onwards. Using an abrupt 3-region Poisson solver and deduced u.i.d level $\left(\sim 10^{16} \mathrm{~cm}^{-3}\right)$, electric field profile was calculated at different reverse biases to yield leakage current density versus peak electric field, $J-E$.

The $J-E$ results are compared to those of wafer C from Ref [4] in Fig. 1. At an electric field of 150 $\mathrm{kV} / \mathrm{cm}$, the leakage current density increases from 0.06 $\mathrm{mA} / \mathrm{cm}^{2}$ to $0.5 \mathrm{~mA} / \mathrm{cm}^{2}$, exceeding the acceptable current limit. A re-growth of structure similar to wafer $\mathrm{C}$ in Ref [4], except without the AlAs layer, yielded higher leakage current densities than wafer $\mathrm{C}$ itself, as shown in Fig. 1. This increase in leakage current density suggests that the wafer quality in the new growth is poorer than that in wafer $\mathrm{C}$. Hence, there is still room for improvement in the dark currents of the $\mathrm{Ga}_{0.88} \operatorname{In}_{0.12} \mathrm{~N}_{0.042} \mathrm{As}_{0.958} \mathrm{p}$-i-n diodes in future growth.

Since the $\mathrm{Ga}_{0.88} \mathrm{In}_{0.12} \mathrm{~N}_{0.042} \mathrm{As}_{0.958} \mathrm{p}$-i-n diodes exceed the current density limit by a small margin, it is still worthwhile to study its photoresponse versus wavelength. Using a tungsten lamp and a monochromator, the photocurrent versus wavelength characteristics was measured on the diodes at room temperature. Due to non-uniformity in composition across the wafer, the measurements were performed on diodes from different parts of the wafer, namely centre, middle and edge.

TABLE 1: Structure details of the GaInNAs p-i-n diode wafer for photoresponse work.

\begin{tabular}{|c|c|}
\hline Layer & Thickness(nm) \\
\hline $\mathrm{p}^{++} \mathrm{GaAs}$ & 20 \\
\hline $\mathrm{p}^{+} \mathrm{GaAs}$ & 480 \\
\hline $\mathrm{p}^{+}$GaInNAs & 50 \\
\hline i GaInNAs & 400 \\
\hline $\mathrm{n}^{+}$GaInNAs & 50 \\
\hline $\mathrm{n}^{+} \mathrm{GaAs}$ & 300 \\
\hline \multicolumn{2}{|c|}{$\mathrm{n}^{+} \mathrm{GaAs}$ substrate } \\
\hline
\end{tabular}

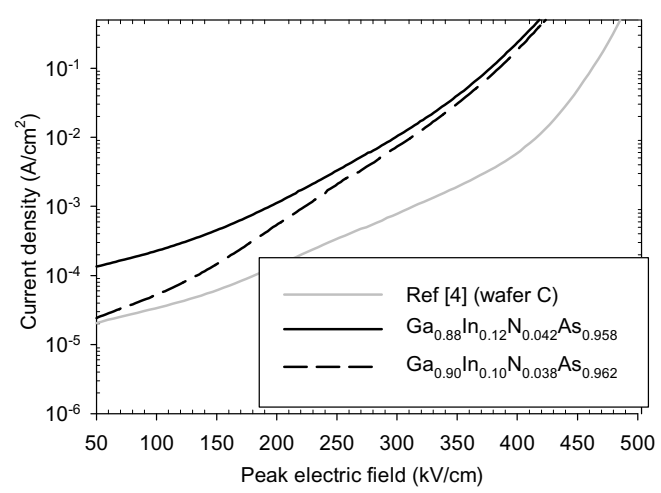

FIG. 1: Reverse leakage current density versus peak electric field of the $\mathrm{Ga}_{0.88} \mathrm{In}_{0.12} \mathrm{~N}_{0.042} \mathrm{As}_{0.958} \mathrm{p}$-i-n diodes at room temperature. The results are compared to that of wafer $\mathrm{C}$ in Ref [4] for the wider bandgap $\mathrm{Ga}_{0.90} \mathrm{In}_{0.10} \mathrm{~N}_{0.038} \mathrm{As}_{0.962}$.

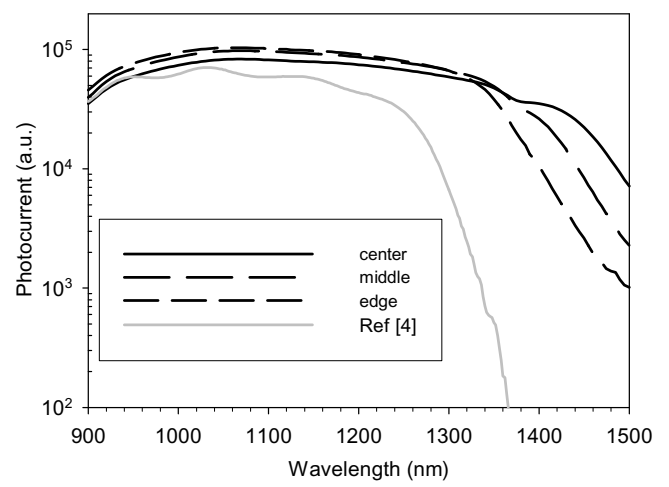

FIG. 2: Photoresponse versus wavelength of the $\mathrm{Ga}_{0.88} \mathrm{In}_{0.12} \mathrm{~N}_{0.042} \mathrm{As}_{0.958} \mathrm{p}$-i-n diodes at $-2 \mathrm{~V}$ and room temperature, compared to the data of wafer $\mathrm{C}$ from Ref [4] for the wider bandgap $\mathrm{Ga}_{0.90} \operatorname{In}_{0.10} \mathrm{~N}_{0.038} \mathrm{As}_{0.962}$. 
Since the C-V data indicated full depletion from $-2 \mathrm{~V}$ onwards, the data for $-2 \mathrm{~V}$ measurements are compared in Fig. 2. Again the data from wafer $\mathrm{C}$ in Ref [4] provide a useful reference and are included in Fig. 2. The photoresponse of the new wafer from all parts of the wafer clearly covers longer wavelengths than before, achieving a relatively constant response of $\sim 1300 \mathrm{~nm}$. The lack of fringes on data from the new wafer compared to the previous wafer is due to the absence of the AlAs layer, which previously formed an optical cavity in the wafer $\mathrm{C}$.

\section{Relationship between $\alpha$ and $\beta$}

For the investigation of relationship between $\alpha$ and $\beta$, a $\mathrm{p}$-i-n diode wafer and a n-i-p diode wafer with $0.8 \mu \mathrm{m}$ i-layer were used. Their structures are described in Table 2. The composition of $\mathrm{Ga}_{0.90} \mathrm{In}_{0.10} \mathrm{~N}_{0.038} \mathrm{As}_{0.962}$ (instead of $\mathrm{Ga}_{0.88} \mathrm{In}_{0.12} \mathrm{~N}_{0.042} \mathrm{As}_{0.958}$ ) and the thicker ilayer were designed to minimize leakage currents, which could make measurements difficult. Also, the dead space effects are likely to be insignificant in $800 \mathrm{~nm}$-thick avalanche layers.

Again, circular mesa diodes were fabricated from these wafers. The investigation relied on the avalanche multiplication versus bias, $M(V)$, data obtained from the photomultiplication measurements of these diodes. The setup employed phase-sensitive detection through mechanically chopped laser light and a lock-in amplifier. Reverse bias to the device-under-test was provided by a Source-Measure-Unit via a small series resistor.

It is well known that, for a given diode, the measured gain is dependent on the carrier injection profile, which in turn depends on the wavelength of laser light used in the measurements. For example, in a $\mathrm{p}-\mathrm{i}-\mathrm{n}$ diode, if a short-wavelength light illuminates the p-side and is absorbed strongly within the p-cladding, then we obtain $M(V)$ data due to pure-electron injection, $M_{e}(V)$. Choosing a wavelength to which the p-cladding is transparent yet is absorbed in the i-layer will generate carriers within the i-layer only, resulting in mixedcarrier injection multiplication data, $M_{\text {mix }}(V)$.

In our photomultiplication measurements, lasers with wavelengths of $532 \mathrm{~nm}$ and $1064 \mathrm{~nm}$ were used. The $532 \mathrm{~nm}$ laser light is strongly absorbed by the top GaAs cladding layer, giving rise to $M_{e}(V)$ and pure-hole multiplication, $M_{h}(V)$, for the p-i-n and the n-i-p diodes, respectively. Using the $1064 \mathrm{~nm}$ light, which is not absorbed in GaAs, mixed-carrier profiles were created within the i-GaInNAs layer, with heavier weighting on electrons and holes, for the p-i-n and the n-i-p diodes, respectively.
The multiplication factor data for both $\mathrm{p}-\mathrm{i}-\mathrm{n}$ and $\mathrm{n}-\mathrm{i}-$ $\mathrm{p}$ diodes are compared in Fig. 3. Despite the different carrier injection profiles achieved using the two different laser lights, $M_{e(h)}(V)$ and $M_{\text {mix }}(V)$ data for a given wafer were indistinguishable, indicating similar values for $\alpha$ and $\beta$ at a given electric field. With $\alpha \sim \beta$, the GaInNAs material is compatible with $\mathrm{Al}_{0.8} \mathrm{Ga}_{0.2} \mathrm{As}$ to form a SAM APD.

TABLE 2: Structure details of the GaInNAs $0.8 \mu \mathrm{m}$ p-i$\mathrm{n}$ and $\mathrm{n}$-i-p diode wafers for investigating relationship between $\alpha$ and $\beta$.

\begin{tabular}{|c|c|c|}
\hline \multicolumn{2}{|c|}{ Layer } & Thickness \\
\hline$p-i-n$ & $n-i-p$ & \\
\hline $\mathrm{p}^{++} \mathrm{GaAs}$ & $\mathrm{n}^{++} \mathrm{GaAs}$ & 20 \\
\hline $\mathrm{p}^{+} \mathrm{GaAs}$ & $\mathrm{n}^{+} \mathrm{GaAs}$ & 480 \\
\hline $\mathrm{p}^{+}$GaInNAs & $\mathrm{n}^{+}$GaInNAs & 50 \\
\hline i GaInNAs & i GaInNAs & 800 \\
\hline $\mathrm{n}^{+}$GaInNAs & $\mathrm{p}^{+}$GaInNAs & 50 \\
\hline $\mathrm{n}^{+} \mathrm{GaAs}$ & $\mathrm{p}^{+} \mathrm{GaAs}$ & $\begin{array}{c}300(p-i-n) \\
2000(n-i-p)\end{array}$ \\
\hline
\end{tabular}

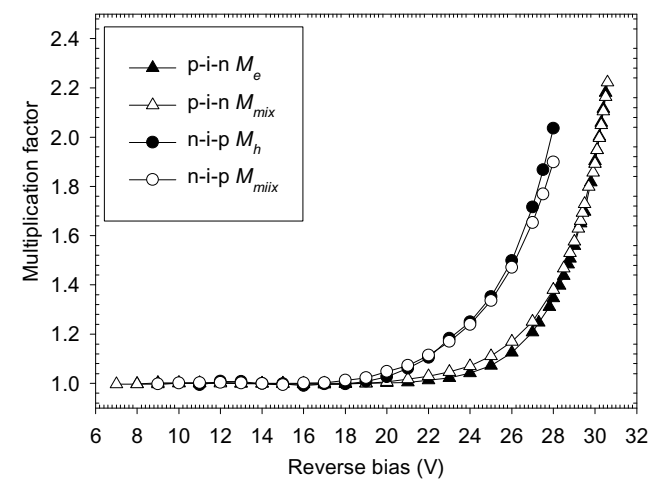

FIG. 3: $\quad M_{e}(V)$ and $M_{\text {mix }}(V)$ for the $0.8 \mu \mathrm{m}$ $\mathrm{Ga}_{0.90} \mathrm{In}_{0.10} \mathrm{~N}_{0.038} \mathrm{As}_{0.962} \mathrm{p}$-i-n and n-i-p diodes.

\section{Conclusions}

A GaInNAs p-i-n diode with suitable photoresponse to cover the $1310 \mathrm{~nm}$ optical communication wavelength is demonstrated. Although its leakage current density has exceeded the limit for applications by a small margin, it is expected that with wafer growth optimization, the GaInNAs material could soon meet the leakage current density requirement whilst retaining its desirable photoresponse properties. Also, comparison of multiplication factors suggests $\alpha \sim \beta$ in this material, satisfying the compatibility consideration when combining with the $\mathrm{Al}_{0.8} \mathrm{Ga}_{0.2} \mathrm{As}$ material to form SAM APDs. Therefore, GaInNAs is suitable for use as absorber material in APDs for 1310/1550 nm wavelength applications. 
This work was supported in part by the Royal Society for the University Research Fellowship to J. S. $\mathrm{Ng}$, the Engineering Physical Sciences Research Council (grants EP/E065007/1 and EP/E063632/1), and the European Commission's Materials for Avalanche Receiver for Ultimate Sensitivity (MARISE) project.

\section{References}

[1] D. S. G. Ong et al., "Optimization of InP APDs for high-speed lightwave systems", J. Lightwave Technol., 27(15), pp. 3294, 2009.

[2] A. Rouvie et al, "180-GHz gain-bandwidth product back-side-illuminated GaInAs-AlInAs APDs, IEEE Photonics Technol. Lett., 21(11), Jun 2009.

[3] B. K. Ng et al., "Excess noise characteristics of $\mathrm{Al}_{0.8} \mathrm{Ga}_{0.2} \mathrm{As}$ avalanche photodiodes", IEEE Photon. Technol. Lett., 14, pp. 522, 2002.

[4] J. S. Ng et al., "Long wavelength bulk GaInNAs $p-i-n$ photodiodes lattice matched to GaAs", $J$. Appl. Phys., 101, 064506, 2007.

[5] J. S. Ng et al., "Effect of impact ionization in the InGaAs absorber on excess noise of avalanche photodiodes", IEEE J. Quan. Electronics, 41(8), pp. 1092-1096, 2005.

[6] A. R. Adams, "Band-structure engineering to control impact ionisation and related high-field processes," IEE Lett., 40(17), 2004.

[7] L. Bellaiche, "Band gaps of lattice-matched (Ga,In)(As,N) alloys", Appl. Phys. Lett., 75(17), pp. $2578,1999$. 